\title{
Minimally invasive tricuspid valve surgery
}

\author{
Abdelrahman Abdelbar^, Ayman Kenawy, Joseph Zacharias \\ Department of Cardiothoracic surgery, Lancashire Heart Centre, Blackpool Teaching Hospital, Blackpool, UK \\ Contributions: (I) Conception and design: A Abdelbar, J Zacharias; (II) Administrative support: J Zacharias; (III) Provision of study materials or \\ patients: A Abdelbar, A Kenawy; (IV) Collection and assembly of data: A Abdelbar, A Kenawy; (V) Data analysis and interpretation: All authors; (VI) \\ Manuscript writing: All authors; (VII) Final approval of manuscript: All authors. \\ Correspondence to: Abdelrahman Abdelbar, FRSC C-Th. Department of Cardiothoracic Surgery, Lancashire Heart Centre, Blackpool Teaching \\ Hospital, Whinny Heys Rd, Blackpool, UK. Email: abdomet@yahoo.com.
}

\begin{abstract}
Tricuspid valve disease carries a very unfavorable prognosis when medically treated. Despite that, surgical intervention is still underperformed for tricuspid valve disease due to the reported high morbidity and mortality from a sternotomy approach. This had led to a shift towards maximizing medical therapy for right ventricular failure and, as a result, a more significant delay in surgical referrals with surgical risks when patients are finally referred. Tricuspid valve patients usually have other co-morbidities resulting from their systemic venous congestion and low flow cardiac output. Minimally invasive tricuspid valve surgery provides less tissue injury and, as a result, less trauma during surgery. This provides a hope for both patients and treating doctors to be more open for providing this procedure with less complications. Isolated minimally invasive tricuspid valve surgery is still not performed as widely as expected. This can be partly due to the adverse outcomes historically labelled to tricuspid valve surgery or by the long journey of learning the surgical team would need to commit to with a minimal access approach. In this article we will review the perioperative pathway, and outcomes of isolated minimally invasive tricuspid valve surgery in the available English literature.
\end{abstract}

Keywords: Tricuspid regurgitation; minimally invasive; video-assisted thoracoscopic surgery

Submitted Mar 15, 2020. Accepted for publication Jul 01, 2020.

doi: $10.21037 /$ jtd-20-1331

View this article at: http://dx.doi.org/10.21037/jtd-20-1331

\section{Introduction}

Tricuspid valve (TV) disease has been increasingly diagnosed within the community due to various reasons which include the increase in intracardiac devices implantation (Figure 1) and prevalence of atrial fibrillation (AF) (1). Despite the benign appearance of tricuspid valve disease, it carries a very poor prognosis when left untreated. TV disease, when it reaches its late stages, will affect other systems which could include liver congestion and renal impairment. This in turn will lead to a higher surgical risk of complications. This has been the main reason for surgical turn down of this group of patients as the reported results from sternotomy surgery remained highly discouraging (2).
Since the introduction of minimally invasive cardiac surgery (MICS) techniques in the late 90s, a lot of work has been done to support adopting this technique and to provide new ideas and solutions for the emerging challenges (3). This was the case with many centers which decided to perform minimally invasive tricuspid surgery (MITS) as a concomitant procedure with mitral valve surgery (4). Yet, due to the rarity of isolated TV surgeries performed in general, it is still difficult to find supporting literature for MITS. It is surprising that despite all the advances in MICS, isolated MITS is still underperformed.

In this article, we are trying to provide a broad view of the perioperative management of isolated MITS patients

$\wedge$ ORCID: 0000-0002-0052-2568. 


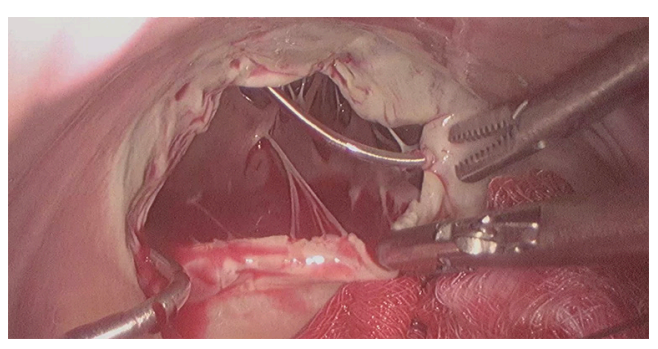

Figure 1 An operative view of a regurgitant tricuspid valve due to perforation and fixation of one leaflet by a pacemaker lead.

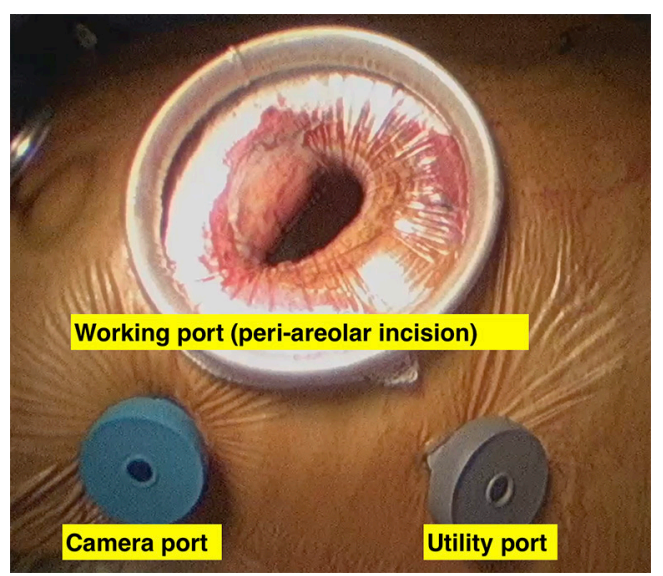

Figure 2 An operative view of a peri-areolar incision with two ports placed.

along with the available results in the English literature.

\section{Surgical technique}

\section{Preoperative preparation}

Routine work up is the same as sternotomy approach which includes echocardiogram, 12 lead electrocardiogram (ECG), chest $\mathrm{X}$-ray, routine blood tests and preoperative examination (5).

In addition to the routine preoperative work up, MICS would require a thorough assessment of the peripheral vascular cannulation sites and the thoracic anatomy (6). Some centers relied on the distal aortic angiography during the routine preoperative coronary angiogram. Other centers insisted on performing a routine CT Aortogram with a follow thorough to the femoral vessels (7). In many occasions, studies have reported that the operative strategy was changed according to CT scan results. Patients with unsuitable femoral vessels or tortuous femoro-iliac vessels were considered to be unsuitable for peripheral cannulation. Another route of cannulation was considered, or patients were turned down to the sternotomy approach (8). Venous anatomy was also examined by the CT scans. The anatomy of the thoracic aorta is also important. Tortuous or calcified thoracic aorta or, sometimes, the presence of chronic type $\mathrm{B}$ aortic dissection has led to change in the cannulation technique and/or myocardial protection strategy (9). Right pleural adhesions are also a very important factor in considering the suitability for the minimal access surgery. The presence of adhesions can be an indication to abandon the procedure in some centres (10). On the other hands, some other surgical teams would carry out the procedure even with adhesions using diathermy or Ligasure device for dissection (11).

\section{Anaesthetic preparations}

There are a few differences in between routine sternotomy and minimal access tricuspid valve surgery in terms of conduction of anaesthesia. One of the differences in anaesthetic practice between centres is the endotracheal intubation. Right lung could be routinely deflated before conduction of cardio-pulmonary bypass (CPB) to enable performing right mini-thoracotomy and place the utility ports (12). A double lumen endotracheal tube was used to achieve this but, it was shown in occasional cases to cause airway trauma leading to bleeding, airway oedema or hoarseness of voice which would prolong the hospital stay of some patients (13). Better results were achieved using a single lumen endotracheal tube with intermittent ventilation (12). Other centres preferred the use of an endobronchial blocker with the single lumen tube to deflate the right lung and avoid desaturation (14).

Anaesthetic preparation would also include insertion of a percutaneous superior vena caval cannula through the jugular vein and sometimes, insertion of a vascular occlusion catheter in the superior vena cava (SVC) distal to the SVC cannula to prevent air lock in the circuit when the right atrium is opened. We will discuss this in detail in the cannulation section.

\section{Surgical procedures}

Surgical incisions vary between the different centres in case of minimally invasive surgery. The size of the incision became smaller with time and with surgical team experience. It started with small incision thoracotomy 

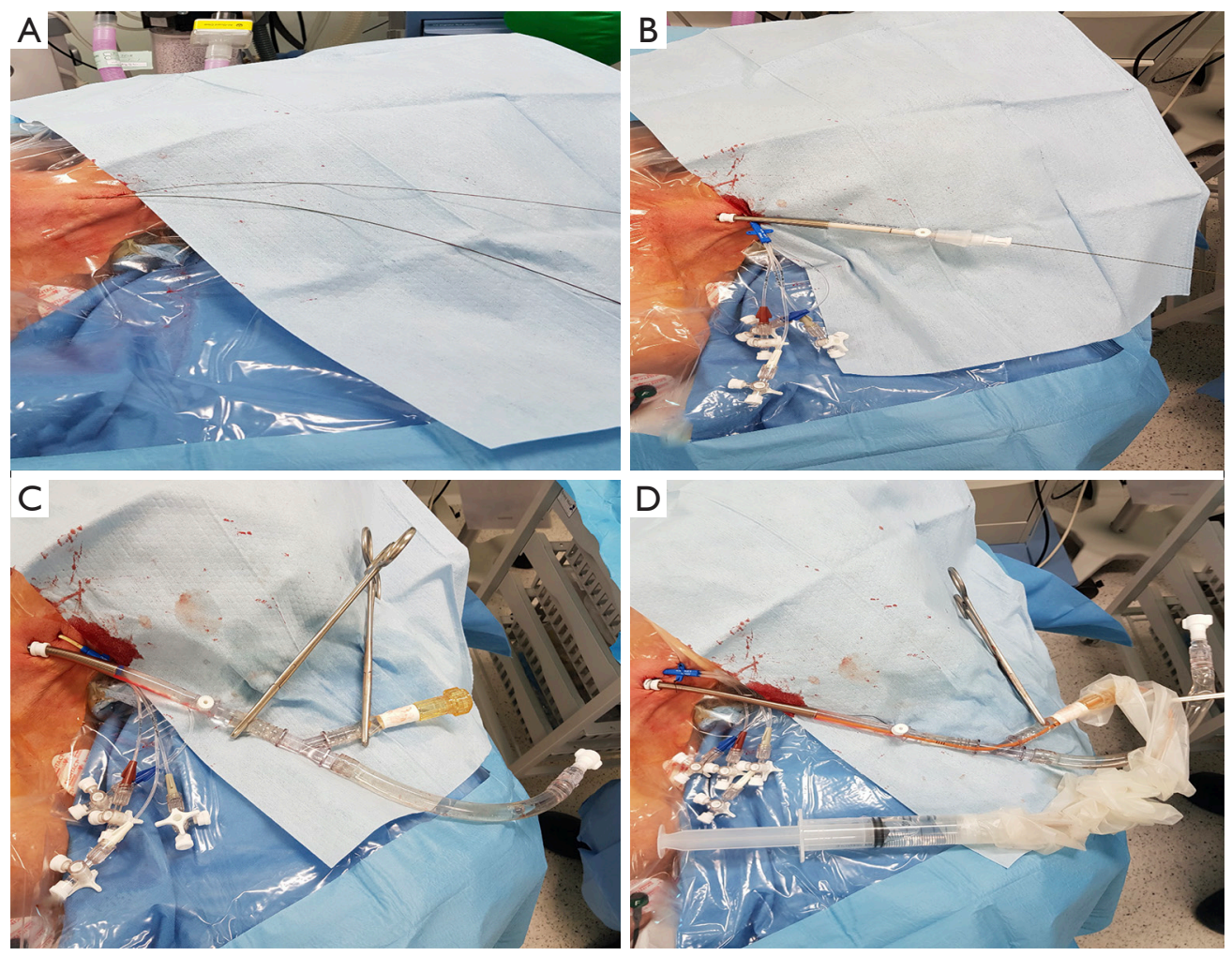

Figure 3 Steps of percutaneous superior vena cava (SVC) cannulation: (A) wires insertion, (B) cannula insertion, (C) three-way connector attached, (D) balloon inserted through the three way connection.

$(8-10 \mathrm{~cm})$ for a direct vision procedure then, the incisions became smaller $(4-6 \mathrm{~cm})$ with the introduction of the video assistance (15). Finally, the incisions became more cosmetic by the introduction the peri areolar incisions (Figure 2) without compromising the quality of the procedure (16). Many centres mentioned using blunt dissection and muscle splitting techniques while performing the mini thoracotomy to promote better healing and less pain post operatively (5).

Venous cannulation in case of MITS is the most variable step between many centres. The main reasons for this variability are the expertise of the team, cost effectiveness and making the surgery more practical and reproducible. Classically, an SVC cannula is inserted percutaneously through the jugular vein, this followed by insertion of the inferior vena cava (IVC) cannula using the femoral vein (17). In both cases, guide wires and cannulae positioning were guided by trans-oesophageal echocardiogram (TOE) (18). Other centres published their results with direct bi-caval cannulation using the standard sternotomy cannulae with good outcomes (19). A very interesting technique has been also utilized using ballooned endotracheal tubes to cannulate both cavae directly while using the tube balloons as occlusion method to avoid air locks (20). In terms of practicality, other centres found that using only a single multistage venous cannula inserted through the femoral vein to be very safe and effective even with right atriotomy (21). In fact, a comparative study showed that using IVC cannulation only through the femoral vein is comparable to using both bi-caval cannulation (22). In the same context, placing an atrial shunt between SVC and IVC after right atriotomy can provide good venous drainage from the SVC through the right atrium to the single IVC cannula with achieving a completely bloodless field (23). Isolation (snaring) of the cavae is also variable between different centres. Some centres used vascular occlusion balloons to isolate both cavae. In this case, they used the opposite side of both femoral and jugular cannulation to insert the balloon catheter and place them distal to the venous cannulae. Other centres only used these balloons to snare the SVC whether by inserting them through the contralateral side as before or by inserting them through the SVC cannula itself (Figure 3) using a three-way connection (24). 


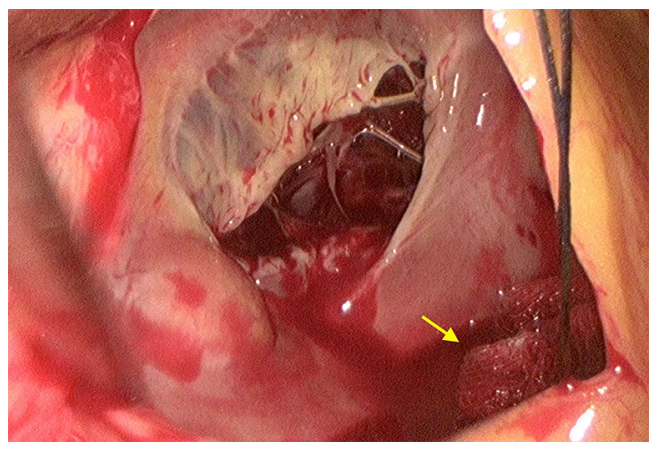

Figure 4 Intraoperative photo to show the small gauze (yellow arrow) on the mouth of the inferior vena cava (IVC).

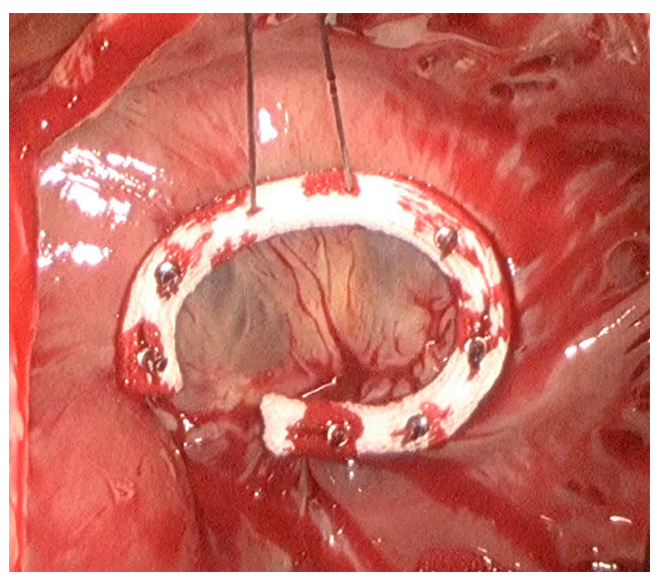

Figure 5 An annuloplasty ring secured in place using the automated knot fixation.

For the purpose of making the procedure easier, some centre adopted more simple techniques in SVC isolation. For example, isolation would be achieved using a standard nylon tape or a large bulldog vascular clamp. In case of IVC isolation, the nylon tape could be used or, simply, place a small swab (Figure 4) on the IVC orifice after right atriotomy (5). Arterial cannulation was done through the femoral arteries in most of the cases. Femoral arteries were assessed for suitability as mentioned in the preoperative section. For the purpose of peripheral arterial cannulation, a small groin cutdown was performed at the same side of venous cannulation (17). Percutaneous cannulation was also performed in some studies when the endo-aortic balloon endoclamp was not used (25). In case of the need for a purpose designed femoral cannula to insert the endo-aortic balloon endoclamp, groin cutdown was mandatory (26). Some centres preferred to perform direct aortic cannulation to avoid the retrograde blood flow (27).

Myocardial protection in MITS would also vary between different teams. Cardioplegic cardiac arrest is one option but, it would require aortic clamping. To achieve this, many centres used an external cross clamp (28). In redo setting, surgeons would avoid dissecting the adhesions around the aorta and would use aortic endo-balloon occlusion clamp to achieve cross clamping (29). Some centres with a good experience with the endo-aortic balloon clamp would use this technique even in primary cases (30). On the other hand, some centres preferred to avoid cross clamping totally by performing beating heart surgery or perform the surgery with ventricular fibrillation and hypothermia (31).

Surgical techniques for repair and replacement in MITS are the same to those in the standard sternotomy approach (Figure 5). There are many reports of achieving satisfactory results with complex repairs performed with the minimally invasive approach (32).

There are many solutions for pacing after the procedure. The most commonly used one in the primary cases is placing the standard epicardial pacing wires into the epicardial surface of the right ventricle (5). Other options are mainly used for the redo cases where dissection of adhesions is avoided to avoid injury of the cardiac structures or the previous bypass grafts. In those cases, pacing through the tricuspid valve using a transvenous pacing catheter inserted preoperatively and repositioned after the repair/ replacement is achieved (33). Another similar option is to place a coronary sinus catheter which will be inserted by the anaesthetic team into the right atrium and positioned after the repair/replacement by the surgeon (34). In some other cases, the standard epicardial pacing wires were placed directly into the endocardial surface of the right ventricle and passed through the tricuspid valve then through the right atriotomy suture line. In those cases, no report of bleeding after removal of the pacing wires was noted (35).

After weaning from $\mathrm{CPB}$, some centres suggested loose closure of the pericardium with placing of a small drain (e.g., Blake Ethicon) in the pericardium and another drain in the right pleura (36). Some other centres place a single drain in the right pleura without closing the pericardium. In redo cases, only one drain is placed in the right pleura (31).

\section{Post-operative care}

Immediate post-operative care of the minimally invasive patients is the same as standard sternotomy patients. Most centres insisted on having an immediate post-operative 
Table 1 A summary of the outcome of the MITS

\begin{tabular}{|c|c|c|c|c|c|c|}
\hline Study & Year & $\begin{array}{l}\text { CPB } \\
\text { perfusion }\end{array}$ & Mortality (MITS) & CVA (MITS) & $\begin{array}{l}\text { Renal complications } \\
\text { (MITS) }\end{array}$ & $\begin{array}{l}\text { Arrythmia/pace- } \\
\text { maker (MITS) }\end{array}$ \\
\hline $\begin{array}{l}\text { Ricci et al. (38)-64 patients; all } \\
\text { had redo surgery; some patients } \\
\text { had concomitant procedures }\end{array}$ & 2014 & Retrograde & $7.9 \%$ & $1.6 \%$ & $7.8 \%$ & $10.4 \%$ \\
\hline $\begin{array}{l}\text { Joseph (28)-12 patients; } \\
\text { isolated Tricuspid surgery } \\
\text { (primary and redo) }\end{array}$ & 2016 & Retrograde & $17 \%$ & $0 \%$ & $8.3 \%$ & $\begin{array}{l}17 \% \text { AF; } 0 \% \text { pace- } \\
\text { maker }\end{array}$ \\
\hline $\begin{array}{l}\text { Maimaiti et al. (32)-49 patients; } \\
\text { all had redo surgery; divided into } \\
\text { MITS and sternotomy groups }\end{array}$ & 2017 & Retrograde & $\begin{array}{l}5 \% \text { (same in the } \\
\text { sternotomy group) }\end{array}$ & $\begin{array}{l}4 \% \text { ( } 0 \% \text { in the } \\
\text { sternotomy group) }\end{array}$ & $\begin{array}{l}13 \% \text { (35\% in the } \\
\text { sternotomy group) }\end{array}$ & $\begin{array}{l}9 \% \text { pacemaker }(15 \% \\
\text { in the sternotomy } \\
\text { group) }\end{array}$ \\
\hline $\begin{array}{l}\text { Färber et al. (39)-104 patients in } \\
\text { three groups: redo-MITS, redo- } \\
\text { sternotomy, primary surgery as } \\
\text { control group }\end{array}$ & 2018 & Retrograde & $\begin{array}{l}7 \% \text { ( } 27 \% \text { in the } \\
\text { sternotomy group } \\
\text { and } 8 \% \text { in the } \\
\text { control group) }\end{array}$ & $\begin{array}{l}2 \%(12 \% \text { in the } \\
\text { sternotomy group } \\
\text { and } 0 \% \text { in the } \\
\text { control group) }\end{array}$ & $\begin{array}{l}13 \% \text { ( } 24 \% \text { in the } \\
\text { sternotomy group and } \\
12 \% \text { in the control } \\
\text { group) }\end{array}$ & $\begin{array}{l}7 \%(12 \% \text { in the } \\
\text { sternotomy group } \\
\text { and } 0 \% \text { in the } \\
\text { control group) }\end{array}$ \\
\hline $\begin{array}{l}\text { Chen et al. }(40)-118 \text { patients; } \\
\text { study was designed to compare } \\
\text { repair to replacement; started } \\
\text { their experience with sternotomy } \\
\text { then shifted to MITS }\end{array}$ & 2019 & Retrograde & $\begin{array}{l}4.6 \%(23.3 \% \text { in } \\
\text { the sternotomy } \\
\text { group) }\end{array}$ & - & - & $0.9 \%$ \\
\hline
\end{tabular}

MITS, minimally invasive tricuspid surgery; CPB, cardio-pulmonary bypass; CVA, cerebrovascular accidents.

chest X-ray to ensure right lung expansion, confirm the position of the right pleural drain and exclude unilateral pulmonary congestion (5). Some centres adopted quick removal of the drains within 24-48 hours post-surgery (37). Other centres left the pericardial drain for 3 to 4 days to protect against late pericardial effusion (32).

\section{Outcomes}

In general, there is a significant lack of prospective randomized trials comparing minimal access surgery to standard sternotomy. In case of minimal access isolated tricuspid surgery, most of the data are collected from single centre experiences, case series and case reports (Table 1). Some relatively large volume studies showed the results of isolated tricuspid valve surgery, but they did not include subgroup comparative analysis between sternotomy and minimally invasive approaches (40). Other studies from highly experienced centres showed the results of concomitant tricuspid valve surgery during mitral valve surgery (41).

\section{Operative times}

Long operative times is a consistent criticism for MICS in general (42). This was thought to be directly related to post-operative complications because, in standard sternotomy surgery, long bypass times are reflecting complicated surgery (43). This was proved not be the case in MICS as long bypass times were planned and, despite that, they have less impact on the patients compared to median sternotomy (44). Interestingly, Maimaiti and colleagues reported shorter bypass times in their MITS group (78.4 $\pm 31.2 \mathrm{~min})$ compared to the median sternotomy $(90.9 \pm 22.8 \mathrm{~min})$. This can be explained by the fact that all their patients had redo surgery (32). Our results showed total bypass times of $139.8 \pm 46.4$ minutes. This also reflects that we used the endovascular occlusion clamp in most of the cases which increases the bypass times (5). Chen and colleagues reported a total bypass time of $74.8 \pm 28.5 \mathrm{~min}$ in their 117 patients with isolated tricuspid surgery patients. In their series $90.7 \%$ of the patients had MITS (40). Ricci and colleagues reported 
a long bypass times of $135.8 \pm 41.9 \mathrm{~min}$, but their series included also concomitant procedures with the MITS (38). We will show in the following sections if the long bypass times had an impact on the results.

\section{Mortality}

Isolated tricuspid valve surgery via sternotomy carries high mortality rates that reaches $50 \%$ in some series (45). Minimally invasive tricuspid valve surgery appeared to have lower mortality rates than the sternotomy approach. In a comparative study, Maimaiti and colleagues (32) showed similar 30-day mortality rate of $5 \%$ between both sternotomy and MITS in redo settings. In the same context, Faber and colleagues showed a mortality of $7 \%$ in the redo MITS group compared to $27 \%$ mortality in the sternotomy group also in redo setting (39). They had a control group in their study which contained only primary MITS with a mortality of $8 \%$. Our results showed a total 30 -day mortality rate of $4.1 \%$ in their MITS both in primary and redo settings (5). The Liepzig group's mortality rate in the redo MITS was $4.2 \%$. Ricci and colleagues performed MITS in high risk patients with a predicted mortality of $11.6 \% \pm 11.7 \%$ but the actual mortality rate was $7.9 \%$ but, in their study, some patients underwent concomitant procedures, e.g., mitral valve surgery or ASD closure (38). Chen and colleagues reported their long experience with reoperative isolated tricuspid valve surgery (40). In their work, they report a significant reduction in mortality when compared their initial utilization of the median sternotomy technique (mortality $23.3 \%$ ) to the mortality of $4.6 \%$ after shifting to MITS.

\section{Blood loss and blood transfusion}

Generally, MICS carries less risk for blood loss compared to standard sternotomy (46). This is believed to be caused by the smaller incision and minimal dissection to achieve a satisfactory view of the operative field (44). Maimaiti and colleagues (32) showed less bleeding during the first 24 hours in the MITS with a mean of $420 \mathrm{~mL}$ compared to $589.6 \mathrm{~mL}$ in the sternotomy group. They also measured the total drainage in both groups and found a mean total of $1,151.7 \mathrm{~mL}$ in the MITS group compared to $2,276.2 \mathrm{~mL}$ in the sternotomy group. Both were statistically significant. They attributed the increased drainage in their study to the general condition of the patient and the need for dissection in these redo cases. Faber and colleagues reported 29\% re-exploration for bleeding in their redo sternotomy group compared to $7 \%$ in the redo MITS group. This has reflected on the blood transfusion rates post operatively. The mean number of units transfused in the MITS group was 4.8 units whereas a mean of 8.7 units were transfused in the redo sternotomy group in their experience (39). Also, in their study, the primary MITS re-exploration for bleeding was $8 \%$. In our experience, the mean blood loss was $301 \mathrm{~mL}$ in total and the transfusion rate was $12.5 \%$ (5). Chen and colleagues performed 118 isolated redo tricuspid valve surgery, 107 of them were MITS. They have published the collective results showing mean blood loss of $250 \mathrm{~mL}$ in the first 24 hours with no blood transfusion at all (40). Ricci and colleagues showed a mean blood loss of $471.5 \mathrm{~mL}$ in their high-risk patients but they did not mention their transfusion rates in their study (38).

\section{Cerebrovascular accidents (CVA)}

For the past two decades, MICS was reported to be associated with a significantly increased risk of CVA compared to standard sternotomy (47). This was always thought to be caused by performing surgery with retrograde cardiopulmonary bypass so, many centres started to shift towards antegrade cardiopulmonary bypass using axillary artery cannulation or direct aortic cannulation (48). Recently, many studies have precluded those finding by reporting equal or less incident of CVA with the utilization of retrograde perfusion (49). In particular to isolated MITS, Maimaiti and colleagues have reported $4 \%$ risk of stroke with compared to no stroke reported in the sternotomy cases (32). Faber and colleagues reported no stroke in their primary MITS group. In their comparison in the redo setting, redo MITS showed 2\% stroke rate compared to $12 \%$ in the redo sternotomy (39). In our experience, we have not encountered any post-operative stroke with MITS (5). Joseph has also encountered no CVA in their MITS published work (28), the same outcome was concluded by Liu and colleagues (50). In high risk patient undergoing MITS, Ricci and colleagues reported an incidence of $1.6 \%$ post-operative stroke (38). This confirms that in selected patients MITS can be performed without any increase in stroke rates.

\section{Renal complications}

In general, renal complications can be higher in patients undergoing isolated tricuspid valve surgery due to their general comorbidity and delayed referral to surgery (51). In 
their redo series in relatively young patients, Moutakiallah and colleagues performed 26 isolated reoperative tricuspid valve surgery. Only two of their patients were performed using MITS technique. They have reported renal failure incidence of $30.8 \%$ (52). In their comparative study, Maimaiti and colleagues reported a higher risk of acute kidney injury (AKI) in their sternotomy group reaching $35 \%$ compared to $13 \%$ in the MITS group (32). They have also reported equal incidence of new renal haemodialysis post-operatively of $13 \%$. Faber and colleague reported $13 \%$ and $24 \%$ new onset dialysis requirement post redo MITS and redo sternotomy respectively. Their primary MITS group showed a new dialysis rate of $12 \%$ (39). Liu and colleagues (50) have reported $5.6 \%$ of their patients requiring renal replacement therapy post MITS. In our institution, $12.5 \%$ of the patients required hemofiltration post operatively (5). Joseph reported that $8.3 \%$ of their patients required renal replacement therapy in the postoperative period (28). In high risk MITS patients, Ricci and colleagues reported $7.8 \%$ risk of acute renal failure requiring renal replacement therapy (38).

\section{Arrythmias and pace-maker implantation}

The increased diagnosis of tricuspid valve regurgitation is thought to be a result of the increased prevalence of atrial fibrillation (AF) and implantation of pacing devices. This would explain why most of the patients undergoing tricuspid will have rhythm problems. Tricuspid valve surgery in general carries high risk of post-operative arrythmia and requirement of pacemaker implantation. Maimaiti and colleagues reported $9 \%$ pacemaker insertion in their MITS compared to $15 \%$ in the sternotomy group (32). The same pattern was reported by Faber and colleagues (39). They reported 7\% new pacemaker insertion in the redo MITS group, $12 \%$ in the redo sternotomy group and zero percent in the primary MITS control group. Interestingly, Chen and colleague reported only $0.9 \%$ incidence of pacemaker insertion in their large series that was performed mainly via MITS (40). Similar results of $1.1 \%$ pacemaker insertion was reported by Liu and colleagues (50). In our experience, there was no rhythm problems requiring pacemaker insertion (5). In the Leipzig experience, $10.4 \%$ of the patient developed brady arrythmia or atrio-ventricular block requiring new pacemaker insertion (25). In General, the incidence of rhythm disturbances after tricuspid valve surgery is relatively high. Fang and colleagues performed 91 redo tricuspid valve surgeries, 77 of them was performed with MITS. They reported $2.2 \%$ incidence of new pacemaker insertion (53).

\section{Postoperative pain}

We did not find reports of pain scores in particular to isolated MITS. Despite that, there is abundant evidence comparing right mini thoracotomy to standard sternotomy (15). Many studies reported less post-operative pain in MICS as opposed to sternotomy (54-57). This is thought to be resulting from keeping the integrity of the sternum which leads to better bony thorax stability. Cohn and colleagues reported similar pain scores in both minimally invasive and sternotomy groups in the first 48 hours. The difference the pain scores became wider from the third day of surgery and continued to progressively show better results in the minimally invasive group (56). In the same context, Orlando and colleagues reported less pain in the minimally invasive group both before and after discharge. This has been translated into a better satisfaction and earlier return to the ordinary day activities (55). In their quality of life study, Leipzig group reported that $94 \%$ of their minimally invasive patient suffered from no pain or mild pain at the most after minimally invasive surgery. They have also reported $43 \%$ return to work in the first 3 weeks with $93 \%$ of the patient preferring to choose the same technique again should they require redo surgery (58). It is impressive to learn that patients who had minimally invasive redo procedure after a previous sternotomy have reported a better experience than their original sternotomy procedure in terms of pain and speedy recovery $(59,60)$.

Following the steps of thoracic surgery, cardiac surgery now is moving towards using regional and local anaesthesia to reduce immediate post-operative pain. For example, Castillo-Sang and colleagues reported $50 \%$ reduction in post-operative narcotics usage after local field block with better pain scores (61). Using pectoral block technique was also described as a method to reduce post-operative pain and opioid use (62).

\section{Hospital stay and cost effectiveness}

In their previously mentioned comparative study Maimaiti and colleagues reported a total hospital stay of $10.1 \pm 6.7$ days in the MITS group compared to $11.3 \pm 7.9$ days in the sternotomy group (P value 0.578$)$ (32). Cohn and colleagues reported a median of 9 days (6-13 days) in their MITS study (40). Faber and colleagues reported longer hospital stays in all the three groups. Their hospital stays were $15 \pm 11$ days in 
the control primary MITS group. In the redo groups, it was $20 \pm 17$ and $18 \pm 10$ days in both redo MITS and redo sternotomy respectively (39). This might be due to the high prevalence of liver cirrhosis among their patients group. In our experience, total hospital stay after MITS was 8 (11.1-8.9) days (5). Ricci and colleagues reported a median of 8 days post-operative hospital stay in their high risk MITS patients' group (38). Joseph showed median post-operative hospital stay of 7 days in their MITS patients (28). Regarding median sternotomy tricuspid surgery, Moutakiallah and colleagues reported the hospital stay of $16.9 \pm 10.1$ days in their 26 patients (only two patients were performed with MITS) (52).

In general, minimally invasive surgery is thought to provide a better cost effectiveness compared to the standard sternotomy surgery $(56,63)$. In a cost analysis study, Vleissis and Bolling reported a significant reduction in cost with minimally invasive mitral surgery. The main areas of saving were in cardiac imaging, radiology, laboratory tests, hospital stays and nursing. They have also reported that less minimally invasive patients require discharging to nursing facilities (64). Despite that all the fore mentioned studies were reporting minimally invasive mitral valve surgery, the same principles can be applied to the MITS. We have shown a relatively shorter hospital stays, blood loss, renal impairment and post-operative pain which would reduce the utilization of the laboratory facilities, blood bank and intensive nursing.

\section{Insights in MICS}

MICS is a very demanding procedure specially at the beginning of the program. It requires a long learning curve, and this length, depends on personal adaptability of each surgeon to this relatively new technique (65). A high level of communication and group training is required for all the team members including surgeons, anaesthetists, perfusionist and nurses (7). It has to be mentioned that most of the criticisms to MICS has been overcome with the progression of experience. Prolonged surgical times has been shown to be significantly reduced with experience (3). Aortic dissection and cannulation complications seemed to be avoided with more planning before surgery even in difficult cases (63). It is clear that with the introduction of the 3-dimension scopes that the view and vision of the surgical field has become much better together with depth perception and manual dexterity (66). This should encourage young surgeons to be more open to this new technology in teams that would elaborate more on a multidisciplinary approach in treatment (heart team) (67). From what we have explained in this review, we hope that we have shared an insight about the advantages of performing MITS in this group of high-risk patients avoiding exposing them to the overwhelming stress of median sternotomy. At the end, a lot of work needs to be done to make sure that MITS is delivered after a structured preparation within the whole operating team.

At present there is a lack of a randomized control trial to support this approach. We hope that a large multicenter registry will be the next step in order to capture the evidence of other operators.

\section{Acknowledgments}

Funding: None.

\section{Footnote}

Provenance and Peer Review: This article was commissioned by the Guest Editors (Jason Ali and Yasir Abu-Omar) for the series "Minimally Invasive Cardiac Surgery" published in Fournal of Thoracic Disease. The article was sent for external peer review organized by the Guest Editors and the editorial office.

Conflicts of Interest: All authors have completed the ICMJE uniform disclosure form (available at http://dx.doi. org/10.21037/jtd-20-1331). The series "Minimally Invasive Cardiac Surgery" was commissioned by the editorial office without any funding or sponsorship. JZ is Proctor for Edwards LifeScience, Abbott and Cryolife. The authors have no other conflicts of interest to declare.

Ethical Statement: The authors are accountable for all aspects of the work ensuring that questions related to the accuracy or integrity of any part of the work are appropriately investigated and resolved.

Open Access Statement: This is an Open Access article distributed in accordance with the Creative Commons Attribution-NonCommercial-NoDerivs 4.0 International License (CC BY-NC-ND 4.0), which permits the noncommercial replication and distribution of the article with the strict proviso that no changes or edits are made and the original work is properly cited (including links to both the formal publication through the relevant DOI and the license). 
See: https://creativecommons.org/licenses/by-nc-nd/4.0/.

\section{References}

1. Arsalan M, Walther T, Smith RL, et al. Tricuspid regurgitation diagnosis and treatment. Eur Heart $\mathrm{J}$ 2017;38:634-8.

2. Yilmaz O, Suri RM, Dearani JA, et al. Functional tricuspid regurgitation at the time of mitral valve repair for degenerative leaflet prolapse: the case for a selective approach. J Thorac Cardiovasc Surg 2011;142:608-13.

3. Czesla M, Götte JM, Doll N. How to establish video assisted, minimally invasive mitral valve surgery. Heart 2012;98:1172-8.

4. Lange R, Piazza N, Günther T. Tricuspid valve regurgitation: indications and operative techniques. Herz 2017;42:653-61.

5. Abdelbar A, Niranjan G, Tynnson C, et al. Endoscopic Tricuspid Valve Surgery is a Safe and Effective Option. Innovations 2020;15:66-73.

6. Ramchandani M, Al Jabbari O, Abu Saleh W, et al. Cannulation Strategies and Pitfalls in Minimally Invasive Cardiac Surgery. Methodist Debakey Cardiovasc J 2016;12:10-3.

7. Heuts S, Olsthoorn J, Maessen J, et al. Planning minimally invasive mitral valve surgery. J Vis Surg 2018;4:212-22.

8. Loor G, Desai M, Roselli E. Pre-Operative 3D CT Imaging for Virtual Planning of Minimally Invasive Aortic Valve Surgery. JACC Cardiovasc Imaging 2013;6:269-71.

9. Rosu C, Bouchard D, Pellerin M, et al. Preoperative vascular imaging for predicting intraoperative modification of peripheral arterial cannulation during minimally invasive mitral valve surgery. Innovations 2015;10:39-43.

10. Dass C, Simpson SA, Steiner RM, et al. Preprocedural Computed Tomography Evaluation for Minimally Invasive Mitral Valve Surgery. J Thorac Imaging 2015;30:386-96.

11. Abdelbar A, Zacharias J. Isolated Endoscopic Tricuspid Valve Surgery. September 2019. doi: 10.25373/ ctsnet.9770324.

12. Malik V, Jha AK, Kapoor PM. Anesthetic challenges in minimally invasive cardiac surgery: Are we moving in a right direction? Ann Card Anaesth 2016;19:489-97.

13. Zhang C, Yue J, Li M, et al. Bronchial blocker versus double-lumen endobronchial tube in minimally invasive cardiac surgery. BMC Pulm Med 2019;19:207.

14. Kim HY, Baek S, Je H, et al. Comparison of the singlelumen endotracheal tube and double-lumen endobronchial tube used in minimally invasive cardiac surgery for the fast track protocol. J Thorac Dis 2016;8:778-83.

15. Ritwick B, Chaudhuri K, Crouch G, et al. Minimally Invasive Mitral Valve Procedures: The Current State. Minim Invasive Surg 2013;2013:679276.

16. Poffo R, Montanhesi P, Toschi A, et al. Periareolar Access for Minimally Invasive Cardiac Surgery the Brazilian Technique. Innovations (Phila) 2018;13:65-9.

17. Nissen A, Abreu J, Ornekian V, et al. Percutaneous and open cannulation for peripheral cardiopulmonary bypass: pearls and pitfalls. J Vis Surg 2018;4:256-6.

18. Wang Y, Gao CQ, Wang G, et al. Transesophageal echocardiography guided cannulation for peripheral cardiopulmonary bypass during robotic cardiac surgery. Chin Med J (Engl) 2012;125:3236-9.

19. Kandakure PR, Batra M, Garre S, et al. Direct Cannulation in Minimally Invasive Cardiac Surgery with Limited Resources. Ann Thorac Surg 2020;109:512-6.

20. Jiang Z, Mei J, Ding F, Shen S, et al. Application of Endovascular Occlusion of Both Caval Veins in Minimally Invasive Isolated Redo Tricuspid Surgery through Right Thoracotomy. Heart Lung Circ 2014;23:186-9.

21. Jiang Z, Mei J, Ding F, et al. Application of Endovascular Occlusion of Both Caval Veins in Minimally Invasive Isolated Redo Tricuspid Surgery through Right Thoracotomy. Heart Lung Circ 2014;23:186-9.

22. Peng R, Shi H, Ba J, et al. Single Femoral Venous Drainage Versus Both Vena Cava Drainage in Isolated Repeat Tricuspid Valve Surgery. Int Heart J 2018;59:518-22.

23. Wu S, Ma L, Li C, et al. Optimizing Venous Drainage for Minimal Access Right Atrial Procedures. Ann Thorac Surg 2019;108:e337-8.

24. Pfannmüller B, Misfeld M, Borger M, et al. Isolated Reoperative Minimally Invasive Tricuspid Valve Operations. Ann Thorac Surg 2012;94:2005-10.

25. Nissen A, Abreu J, Ornekian V, et al. Our preferred techniques for both direct and percutaneous femoral cannulation in minimally invasive mitral surgery. Asvide 2018;5:930.

26. Van der Merwe J, Casselman F, Van Praet F. The principles of minimally invasive atrioventricular valve repair surgery utilizing endoaortic balloon occlusion technology: how to start and sustain a safe and effective program. J Vis Surg 2019;5:72-85.

27. Grossi EA, Loulmet D, Schwartz C, et al. Minimally Invasive Valve Surgery With Antegrade Perfusion Strategy Is Not Associated With Increased Neurologic Complications. Ann Thorac Surg 2011;92:1346-9.

28. Joseph L. Minimal access tricuspid valve surgery. Asvide 
2017;4:345.

29. Casselman FP, La Meir M, Jeanmart H, et al. Endoscopic Mitral and Tricuspid Valve Surgery After Previous Cardiac Surgery. Circulation 2007;116:I270-5.

30. Marullo AG, Irace F, Vitulli P, et al. Recent Developments in Minimally Invasive Cardiac Surgery: Evolution or Revolution? Biomed Res Int 2015;2015:483025.

31. Misfeld M, Davierwala P, Banusch J, et al. Minimally invasive, beating heart tricuspid valve surgery in a redo case. Asvide 2017;6:347.

32. Maimaiti A, Wei L, Yang Y, et al. Benefits of a right anterolateral minithoracotomy rather than a median sternotomy in isolated tricuspid redo procedures. J Thorac Dis 2017;9:1281-8.

33. Lei Q, Wei X, Huang K, et al. Intraoperative Implantation of Temporary Endocardial Pacing Catheter During Thoracoscopic Redo Tricuspid Surgery. Heart Lung Circ 2019;28:1121-6.

34. Lebon JS, Couture P, Rochon A, et al. The Endovascular Coronary Sinus Catheter in Minimally Invasive Mitral and Tricuspid Valve Surgery: A Case Series. J Cardiothorac Vasc Anesth 2010;24:746-51.

35. Abdelbar A, Laswaski G, Zacharias J. An Endoscopic Solution to a Residual Postinfarct Ventricular Septal Defect. December 2019. doi:10.25373/ctsnet.11310929.

36. Durdu MS. Comparison of Minimal Invasive Cardiac Surgery Incisions: Periareolar Approach in the Female Patients. Anatol J Cardiol 2018;20:283-8.

37. Li M, Zhang J, Gan T, et al. Enhanced recovery after surgery pathway for patients undergoing cardiac surgery: a randomized clinical trial. Eur J Cardiothorac Surg 2018;54:491-7.

38. Ricci D, Boffini M, Barbero C, et al. Minimally invasive tricuspid valve surgery in patients at high risk. J Thorac Cardiovasc Surg 2014;147:996-1001.

39. Färber G, Tkebuchava S, Dawson R, et al. Minimally Invasive, Isolated Tricuspid Valve Redo Surgery: A Safety and Outcome Analysis. Thorac Cardiovasc Surg 2018;66:564-71.

40. Chen J, Hu K, Ma W, et al. Isolated reoperation for tricuspid regurgitation after left-sided valve surgery: technique evolution. Eur J Cardiothorac Surg 2020;57:142-50

41. Lee TC, Desai B, Glower D. Results of 141 Consecutive Minimally Invasive Tricuspid Valve Operations: An 11Year Experience. Ann Thorac Surg 2009;88:1845-50.

42. Chaney MA, Durazo-Arvizu RA, Fluder EM, et al. Portaccess minimally invasive cardiac surgery increases surgical complexity, increases operating room time, and facilitates early postoperative hospital discharge. Anesthesiology 2000;92:1637-45.

43. Rustum S, Fleissner F, Beckmann E, et al. Is There an Upper Limit to Cardiopulmonary Bypass Times? Annals of Circulation 2017;2:003-007.

44. Qiu Z, Chen X, Xu Y, et al. Does full sternotomy have more significant impact than the cardiopulmonary bypass time in patients of mitral valve surgery? J Cardiothorac Surg 2018;13:29.

45. Topilsky Y, Maltais S, Medina Inojosa J, et al. Burden of Tricuspid Regurgitation in Patients Diagnosed in the Community Setting. JACC Cardiovasc Imaging 2019;12:433-42.

46. Doenst T, Diab M, Sponholz C, et al. The Opportunities and Limitations of Minimally Invasive Cardiac Surgery. Dtsch Arztebl Int 2017;114:777-84.

47. Williams RD, Foley N, Vyas R, et al. Predictors of Stroke After Minimally Invasive Mitral Valve Surgery Without the Cross-Clamp. Semin Thorac Cardiovasc Surg 2020;32:47-56.

48. Murzi M, Cerillo A, Miceli A, et al. Antegrade and retrograde arterial perfusion strategy in minimally invasive mitral-valve surgery: a propensity score analysis on 1280 patients. Eur J Cardiothorac Surg 2013;43:e167-72.

49. Modi P, Hassan A, Chitwood W. Minimally invasive mitral valve surgery: a systematic review and meta-analysis. Eur J Cardiothorac Surg 2008;34:943-52.

50. Liu S, Chen JM, Wang WS, et al. Short-term outcomes of minimally invasive reoperation for tricuspid regurgitation after left-sided valve surgery. Zhonghua Wai Ke Za Zhi 2019;57:898-901.

51. Sung K, Park P, Park K, et al. Is tricuspid valve replacement a catastrophic operation? Eur J Cardiothorac Surg 2009;36:825-9.

52. Moutakiallah Y, Aithoussa M, Atmani N, et al. Reoperation for isolated rheumatic tricuspid regurgitation. J Cardiothorac Surg 2018;13:104.

53. Fang L, Li W, Zhang W, et al. Mid-term results and risks of isolated tricuspid valve reoperation following left-sided valve surgery. Eur J Cardiothorac Surg 2018;53:1034-9.

54. Glower D. Mitral valve operation via Port Access versus median sternotomy. Eur J Cardiothorac Surg 1998;14:S143-147.

55. Santana O, Reyna J, Grana R, et al. Outcomes of Minimally Invasive Valve Surgery Versus Standard Sternotomy in Obese Patients Undergoing Isolated Valve Surgery. Ann Thorac Surg 2011;91:406-10. 
56. Cohn LH, Adams D, Couper G, et al. Minimally Invasive Cardiac Valve Surgery Improves Patient Satisfaction While Reducing Costs of Cardiac Valve Replacement and Repair. Ann Surg 1997;226:421-6.

57. Liu H, Emelife PI, Prabhakar A, et al. Regional Anesthesia Considerations for Cardiac Surgery. Best Pract Res Clin Anaesthesiol 2019;33:387-406.

58. Walther T, Falk V, Metz S, et al. Pain and quality of life after minimally invasive versus conventional cardiac surgery. Ann Thorac Surg 1999;67:1643-7.

59. Felger JE, Chitwood W, Nifong L, et al. Evolution of mitral valve surgery: toward a totally endoscopic approach. Ann Thorac Surg 2001;72:1203-8.

60. Casselman FP. Mitral Valve Surgery Can Now Routinely Be Performed Endoscopically. Circulation 2003;108:II48-54.

61. Castillo-Sang M, Bartone C, Palmer C, et al. Fifty Percent Reduction in Narcotic Use After Minimally Invasive Cardiac Surgery Using Liposomal Bupivacaine.

Cite this article as: Abdelbar A, Kenawy A, Zacharias J. Minimally invasive tricuspid valve surgery. J Thorac Dis 2021;13(3):1982-1992. doi: 10.21037/jtd-20-1331
Innovations (Phila) 2019;14:512-8.

62. Yalamuri S, Klinger R, Bullock W, et al. Pectoral Fascial (PECS) I and II Blocks as Rescue Analgesia in a Patient Undergoing Minimally Invasive Cardiac Surgery. Reg Anesth Pain Med 2017;42:764-6.

63. Navia JL, Cosgrove D. Minimally invasive mitral valve operations. Ann Thorac Surg 1996;62:1542-4.

64. Vleissis AA, Bolling S. Mini-Reoperative Mitral Valve Surgery. J Card Surg 1998;13:468-70.

65. Holzhey DM, Seeburger J, Misfeld M, et al. Learning Minimally Invasive Mitral Valve Surgery. Circulation 2013;128:483-91.

66. Zacharias J, Perier P. Seven Habits of Highly Effective Endoscopic Mitral Surgeons. Innovations (Phila) 2020;15:11-6.

67. Bonatti J. Minimally invasive cardiac surgery—from early steps to consolidation. Indian J Thorac Cardiovasc Surg 2018;34:84-5. 